\title{
AN INVENTORY MANAGEMENT SYSTEM FOR DETERIORATING ITEMS WITH RAMP TYPE AND QUADRATIC DEMAND: A STRUCTURAL COMPARATIVE STUDY
}

\author{
Biswaranjan Mandal \\ Associate Professor of Mathematics \\ Acharya Jagadish Chandra Bose College, Kolkata
}

\begin{abstract}
The present paper deals with an inventory management system with ramp type and quadratic demand rates. A constant deterioration rate is considered into the model. In the two types models, the optimum time and total cost are derived when demand is ramp type and quadratic. A structural comparative study is demonstrated here by illustrating the model with sensitivity analysis.
\end{abstract}

\section{KEYWORDS}

Inventory, ramp type, quadratic, deterioration.

\section{INTRODUCTION}

The economic order quantity model is the oldest inventory management model. An extensive research work has already been done by many researchers like Donaldson W.A.[1], Silver E.A.[2], Mandal and Pal[3]etc on inventory model assuming mostly on two types of time dependent demands - linear and exponential. Linear time dependent demand implies a steady increase or decrease in demand which is not realistic in real market. Again an exponential time varying demand is not realistic because in the real market situations, demand is unlikely to vary with a rate which is so high as exponential. Therefore we developed here two types of inventory models. First, effort has been made to analyze an inventory model for anitem that deteriorates at a constant rate, assuming the demand rate a ramp typefunction of time. Such type of demand pattern is generally seen in the case ofany new brand of consumer goods coming to the market. The demand rate forsuch items increases with time upto a certain time and then ultimately stabilizes and becomes constant. It is believed that such type of demand rate is quiterealistic, vide, Hill [61]. Second, the quadratic time dependent demand seems to be the better representation of time-varying market demand.In this context few researchers like BiswaranjanMandal[4], M Cheng et al [ 5] and Ghosh et al [6] are noteworthy.

Finally numerical examples are done to illustrate the theory. The sensitivity of the optimal solution to change in the parameter values is examined and discussed. Also the comparative study between two types of inventory models are done along with finding its conclusion.

\section{Assumptions And Notations}

The mathematical models are developed under the following assumptions and notations: 
International Journal on Soft Computing (IJSC) Vol.11, No.1/2/3/4, November 2020

(i) Replenishment size is constant and replenishment rate is infinite.

(ii) Lead time is zero.

(iii) $\mathrm{T}$ is the fixed length of each production cycle.

(iv) $\quad C_{h}$ is the inventory holding cost per unit per unit time.

(v) $\quad C_{0}$ is the ordering cost/order.

(vi) $\quad C_{d}$ is the cost of each deteriorated unit.

(vii) $\mathrm{T}$ is the cycle time.

(viii) $\mathrm{TC}$ is the average total cost per unit time.

(ix) A constant fraction $\theta$ of the on-hand inventory deteriorates per unit time. A deteriorated item is lost.

(x) Shortages are not allowed.

(xi) The demand rate $\mathrm{R}(\mathrm{t})$ is assumed in the model

(xii) There is no repair or replacement of the deteriorated items.

\section{Mathematical Models}

\section{Model 1: An inventory model with ramp type demand rate.}

In this mode, the demand rate $\mathrm{R}(\mathrm{t})$ is assumed to be a ramp type function of time :

$$
\mathrm{R}(\mathrm{t})=D_{0}[\mathrm{t}-(\mathrm{t}-\mu) \mathrm{H}(\mathrm{t}-\mu)], D_{0}>0
$$

where $\mathrm{H}(\mathrm{t}-\mu)$ is the well-known Heaviside's function defined as follows :

$$
\begin{gathered}
H(t-\mu)=1, t \geq \mu \\
=0, \mathrm{t}<\mu
\end{gathered}
$$

Let $\mathrm{I}(\mathrm{t})$ be the on-hand inventory at any time $\mathrm{t}$. The differential equations which the on-hand inventory $\mathrm{I}(\mathrm{t})$ must satisfy during the cycle time $\mathrm{T}$ is the following

$$
\frac{d I(t)}{d t}+\theta I(t)=-R(t), 0 \leq t \leq T
$$

In this model, we assume $\mu<\mathrm{t} 1$ and therefore the above governing equation becomes

$$
\begin{aligned}
& \frac{d I(t)}{d t}+\theta I(t)=-D_{0} t, 0 \leq t \leq \mu \\
& \text { and } \frac{d I(t)}{d t}+\theta I(t)=-D_{0} \mu, \mu \leq t \leq T
\end{aligned}
$$

Solutions of the equations (2) and (3) are the following:

$$
I(t)=-D_{0}\left(\frac{t}{\theta}-\frac{1}{\theta^{2}}\right)+e^{-\theta t}\left(Q-\frac{D_{0}}{\theta^{2}}\right), 0 \leq t \leq \mu
$$


And $I(t)=\frac{D_{0} \mu}{\theta}\left(e^{\theta(T-t)}-1\right), \mu \leq t \leq T$

From (4) and (5), we get

$Q=\frac{D_{0}}{\theta^{2}}\left(1-e^{\theta \mu}\right)+\frac{D_{0} \mu}{\theta}\left(1+e^{\theta T}-e^{\theta \mu}\right)$

Or $Q=D_{0} \mu\left(\frac{\theta}{2} T^{2}+T-\frac{\theta}{2} \mu^{2}-\frac{3 \mu}{2}\right)\left(\right.$ by using $e^{\theta}=1+\theta+\frac{\theta^{2}}{2}$ as $\left.\mathrm{O}\left(\theta^{3}\right)<<1\right)(6)$

Total Cost: The total cost comprises of the sum of the setup cost, holding cost and deteriorating cost.

1. Setup Cost $=\frac{C_{o}}{T}$

2. Holding cost $=\frac{C_{h}}{T} \int_{0}^{T} I(t) d t=\frac{C_{h}}{T}\left[\int_{0}^{\mu} I(t) d t+\int_{\mu}^{T} I(t) d t\right]$

$$
\begin{gathered}
=\frac{C_{h}}{T}\left[\frac{D_{0} \mu^{2}}{2 \theta}-\frac{D_{0} \mu T}{\theta}+\frac{D_{0} \mu}{\theta^{2}} e^{\theta(T-\mu)}-\left(Q-\frac{D_{0}}{\theta^{2}}\right) \frac{1}{\theta}\left(e^{-\theta \mu}-1\right)\right] \\
=\frac{C_{h} D_{0} \mu}{T}\left(-\mu^{2}+\frac{\mu^{3} \theta}{4}+\frac{\mu^{4} \theta^{2}}{4}-\frac{\mu^{2} \theta T}{2}+\frac{T^{2}}{2}+\frac{\mu \theta T^{2}}{2}-\frac{\mu^{2} \theta^{2} T^{2}}{4}\right] \\
\text { (by using } \left.e^{\theta}=1+\theta+\frac{\theta^{2}}{2}, \text { as } \mathrm{O}\left(\theta^{3}\right)<<1\right)
\end{gathered}
$$

3. Deteriorating cost $=\frac{\theta C_{d}}{T} \int_{0}^{T} I(t) d t$

$$
=\frac{C_{d} D_{0} \mu \theta}{T}\left(-\mu^{2}+\frac{\mu^{3} \theta}{4}+\frac{\mu^{4} \theta^{2}}{4}-\frac{\mu^{2} \theta T}{2}+\frac{T^{2}}{2}+\frac{\mu \theta T^{2}}{2}-\frac{\mu^{2} \theta^{2} T^{2}}{4}\right]
$$

Therefore the average total cost per unit time is given by $\mathrm{TC}(\mathrm{T})=$ Setup cost + holding cost + deteriorating cost $=\frac{C_{o}}{T}+\frac{\left(C_{h}+\theta C_{d}\right) D_{0} \mu}{T}\left(-\mu^{2}+\frac{\mu^{3} \theta}{4}+\frac{\mu^{4} \theta^{2}}{4}-\frac{\mu^{2} \theta T}{2}+\frac{T^{2}}{2}+\frac{\mu \theta T^{2}}{2}-\frac{\mu^{2} \theta^{2} T^{2}}{4}\right]$

For minimum, the necessary condition is $\frac{d T C}{d T}=0$ 
International Journal on Soft Computing (IJSC) Vol.11, No.1/2/3/4, November 2020

Or, $\frac{D_{0} \mu}{2}\left(1+\mu \theta-\frac{\mu^{2} \theta^{2}}{2}\right) T^{2}+D_{0} \mu^{3}\left(1-\frac{\mu \theta}{4}-\frac{\mu^{2} \theta^{2}}{4}\right)-\frac{C_{0}}{C_{h}+\theta C_{d}}=0$

Which is the equation for optimum solution.

Let $T^{*}$ be the positive real root of the above equation (11), then $T^{*}$ is the optimum cycle time.

The optimum average total cost of $\mathrm{TC}(\mathrm{T})$ is $\mathrm{TC}\left(T^{*}\right)$.

Note: If there be no deterioration i.e. $\theta=0$, the equation (10) becomes

$$
\frac{D_{0} \mu}{2} T^{2}+D_{0} \mu^{3}-\frac{C_{0}}{C_{h}}=0 \text { or } T=\sqrt{\left(\frac{2 C_{o}}{D_{0} \mu C_{h}}-2 \mu^{2}\right)}
$$

\section{NUMERICAL EXAMPLE}

For an inventory system, let the values of parameters be as follows:

$$
C_{o}=\$ 100 ; C_{h}=\$ 10 ; C_{d}=\$ 100 ; D_{0}=100 \text { units; } \mu=0.12 \text { year; } \theta=0.01
$$

Solving the quadratic equation (11) with the above numerical values, we find the optimum values of $\mathrm{T}$ as $T^{*}=1.22$ year.

The optimum values of $\mathrm{Q}$, setup cost, holding cost and deteriorating cost are $Q^{*}=12.57$ units, Setup cost ${ }^{*}=$ Rs 81.97, Holding cost* $=$ Rs 71.86 and Deteriorating cost* $=$ Rs 7.19.

The minimum average total cost per unit time is found to be $T C\left(T^{*}\right)=$ Rs 161.02 .

\section{Sensitivity AnALYSIS}

We now study the effects of increasing rate of deteriorating items on the optimal average costs and cycle time. The results of this analysis are shown in the following table.

\begin{tabular}{|c|c|c|c|c|c|c|}
\hline \multirow{2}{*}{$\theta$} & \multicolumn{7}{|c|}{ Optimum values of } \\
\cline { 2 - 7 } & $\mathrm{T}$ & $\mathrm{Q}$ & $\begin{array}{c}\text { Setup } \\
\text { cost }\end{array}$ & $\begin{array}{c}\text { Holding } \\
\text { cost }\end{array}$ & $\begin{array}{c}\text { Deteriorating } \\
\text { cost }\end{array}$ & Total cost \\
\hline 0.01 & 1.22 & 12.57 & 81.97 & 71.86 & 7.19 & 161.02 \\
\hline 0.02 & 1.16 & 11.92 & 86.21 & 68.26 & 13.65 & 168.12 \\
\hline 0.03 & 1.12 & 11.50 & 89.29 & 65.87 & 19.76 & 174.92 \\
\hline 0.04 & 1.08 & 11.08 & 92.59 & 63.48 & 25.39 & 181.46 \\
\hline 0.05 & 1.04 & 10.96 & 96.15 & 61.07 & 30.54 & 187.76 \\
\hline 0.06 & 1.00 & 10.19 & 100.00 & 58.65 & 35.19 & 193.84 \\
\hline 0.07 & 0.97 & 9.87 & 103.09 & 56.85 & 39.79 & 199.73 \\
\hline 0.08 & 0.94 & 9.54 & 106.38 & 44.05 & 44.03 & 205.45 \\
\hline 0.09 & 0.92 & 9.33 & 108.70 & 53.84 & 48.46 & 211.00 \\
\hline 0.10 & 0.89 & 8.99 & 112.36 & 52.01 & 52.01 & 216.38 \\
\hline
\end{tabular}

Analyzing the results given in the above table, the following observations are made: 
(i) When the rate of deterioration $\theta$ increases, the optimum values Setup cost, Deteriorating cost and Total cost increase.

(ii) The optimum values of $\mathrm{T}, \mathrm{Q}$ and Holding cost decrease with increases in the values of rate of deterioration $\theta$.

\section{Model 2: An inventory model with quadratic demand rate.}

In the present model, we discussed a deterministic inventory model having a quadratic demand function with a constant deteriorating items. The demand rate function is considered as

$$
R(t)=a+b t+c t^{2} \text {, where } \mathrm{a}>0, b \neq 0, c \neq 0 \text { at time } \mathrm{t} \text { and "a" is initial demand. }
$$

The differential equation which the on-hand inventory $I(t)$ must satisfies in the cycle time $\mathrm{T}$ is the following:

$$
\frac{d I(t)}{d t}+\theta I(t)=-\left(a+b t+c t^{2}\right), 0 \leq t \leq T
$$

The boundary conditions are $\mathrm{I}(0)=\mathrm{Q}, \mathrm{I}(\mathrm{T})=0$.

The solution of the equation (13) is

$$
\begin{aligned}
I(t)= & e^{-\theta t}\left[\int_{t}^{T}\left(a+b t+c t^{2}\right) e^{\theta t} d t\right] \\
& =\left(\frac{a+b T+c T^{2}}{\theta}-\frac{b+2 c t}{\theta^{2}}+\frac{2 c}{\theta^{3}}\right) e^{\theta(T-t)}-\frac{a+b t+c t^{2}}{\theta}+\frac{b+2 c t}{\theta^{2}}-\frac{2 c}{\theta^{3}}
\end{aligned}
$$

Using $\mathrm{I}(0)=\mathrm{Q}$, we get

$$
\begin{gathered}
\mathrm{Q}=\left(\frac{a+b T+c T^{2}}{\theta}-\frac{b}{\theta^{2}}+\frac{2 c}{\theta^{3}}\right) e^{\theta T}-\frac{a}{\theta}+\frac{b}{\theta^{2}}-\frac{2 c}{\theta^{3}} \\
=\left(a+\frac{2 c}{\theta^{2}}\right) T+\left(\frac{a \theta}{2}+\frac{b}{2}+\frac{2 c}{\theta}\right) T^{2}+\left(\frac{b \theta}{2}+c\right) T^{3}+\frac{c \theta}{2} T^{4} \\
\quad\left(\text { by using } e^{\theta}=1+\theta+\frac{\theta^{2}}{2} \text { as } \mathrm{O}\left(\theta^{3}\right)<<1\right)
\end{gathered}
$$

Total Cost: The total cost comprises of the sum of the setup cost, holding cost and deteriorating cost.

1. Setup cost $=\frac{C_{o}}{T}$

2. Holding cost $=\frac{C_{h}}{T} \int_{0}^{T} I(t) d t$ 
International Journal on Soft Computing (IJSC) Vol.11, No.1/2/3/4, November 2020

$$
=\frac{C_{h}}{T} \int_{0}^{T}\left[\left(\frac{a+b T+c T^{2}}{\theta}-\frac{b+2 c T}{\theta^{2}}+\frac{2 c}{\theta^{3}}\right) e^{\theta(T-t)}-\frac{a+b t+c t^{2}}{\theta}+\frac{b+2 c t}{\theta^{2}}-\frac{2 c}{\theta^{3}}\right] d t
$$

$=\frac{C_{h}}{T}\left[\frac{a T^{2}}{2}+\frac{b T^{3}}{2}+\frac{c T^{4}}{2}\right]=\frac{C_{h}}{2}\left[a T+b T^{2}+c T^{3}\right]\left(\right.$ by using $e^{\theta}=1+\theta+\frac{\theta^{2}}{2}$, as $\left.\mathrm{O}\left(\theta^{3}\right)<<1\right)$

3. Deteriorating cost $=\frac{\theta C_{d}}{T} \int_{0}^{T} I(t) d t=\frac{\theta C_{d}}{2}\left[a T+b T^{2}+c T^{3}\right]$

Therefore the average total cost per unit time is given by

$\mathrm{TC}(\mathrm{T})=$ Setup cost + holding cost + deteriorating cost

$$
=\frac{C_{o}}{T}+\frac{\left(C_{h}+\theta C_{d}\right)}{2}\left[a T+b T^{2}+c T^{3}\right]
$$

For minimum, the necessary condition is $\frac{d T C}{d T}=0$

$$
\text { Or, } 3 c T^{4}+2 b T^{3}+a T^{2}-\frac{2 C_{0}}{C_{h}+\theta C_{d}}=0
$$

Which is the equation for optimum solution.

\section{NUMERICAL EXAMPLE}

For an inventory system, let the values of parameters be as follows:

$$
C_{o}=\$ 100 ; C_{h}=\$ 10 ; C_{d}=\$ 100 ; D_{0}=100 \text { units; } \theta=0.01 ; \mathrm{a}=5 ; \mathrm{b}=3 ; \mathrm{c}=2 \text {. }
$$

Solving the fourth order equation (20) with the above numerical values, we find the optimum values of $\mathrm{T}$ as $T^{*}=1.02$ year.

The optimum values of $\mathrm{Q}$, setup cost, holding cost and deteriorating cost are $Q^{*}=41225$ units, Setup cost* ${ }^{*}=$ Rs 98.04, Holding cost* ${ }^{*}$ Rs 51.72 and Deteriorating cost* $=$ Rs5.17.

The minimum average total cost per unit time is found to be $T C\left(T^{*}\right)=\mathrm{Rs} 154.93$.

\section{Sensitivity ANALYSIS}

We now study the effects of increasing rate of deteriorating items on the optimal average costs and cycle time. The results of this analysis are shown in the following table.

\begin{tabular}{|c|c|c|c|c|c|c|}
\hline \multirow{2}{*}{$\theta$} & \multicolumn{7}{|c|}{ Optimum values of } \\
\cline { 2 - 7 } & $\mathrm{T}$ & $\mathrm{Q}$ & $\begin{array}{c}\text { Setup } \\
\text { cost }\end{array}$ & $\begin{array}{c}\text { Holding } \\
\text { cost }\end{array}$ & $\begin{array}{c}\text { Deteriorating } \\
\text { cost }\end{array}$ & Total cost \\
\hline 0.01 & 1.02 & 41225.00 & 98.04 & 51.72 & 5.17 & 154.93 \\
\hline 0.02 & 0.99 & 10104.48 & 101.01 & 49.15 & 9.83 & 159.99 \\
\hline
\end{tabular}


International Journal on Soft Computing (IJSC) Vol.11, No.1/2/3/4, November 2020

\begin{tabular}{|l|l|l|l|l|l|l|}
\hline 0.03 & 0.97 & 4444.80 & 103.10 & 47.49 & 14.25 & 164.84 \\
\hline 0.04 & 0.94 & 2446.21 & 106.38 & 45.06 & 18.02 & 169.46 \\
\hline 0.05 & 0.92 & 1559.88 & 108.70 & 43.48 & 21.74 & 173.92 \\
\hline 0.06 & 0.90 & 1061.40 & 111.11 & 41.94 & 25.16 & 178.21 \\
\hline 0.07 & 0.88 & 769.79 & 113.64 & 40.43 & 28.30 & 182.37 \\
\hline 0.08 & 0.87 & 588.68 & 114.94 & 39.69 & 31.75 & 186.38 \\
\hline 0.09 & 0.85 & 458.72 & 117.65 & 38.23 & 34.41 & 190.29 \\
\hline 0.10 & 0.84 & 370.98 & 119.05 & 37.51 & 37.51 & 194.07 \\
\hline
\end{tabular}

Analyzing the results given in the above table, the following observations are made:

(i) When the rate of deterioration $\theta$ increases, the optimum values Setup cost, Deteriorating cost and Total cost increase.

(ii) The optimum values of $\mathrm{T}, \mathrm{Q}$ and Holding cost decrease with increases in the values of rate of deterioration $\theta$.

(iii) The similar nature is observed for both the model 1 and model 2.

\section{Comparative Study Between Two Models}

The comparative study in numerical and graphical is performed here on the basis of the above data.

\begin{tabular}{|c|c|c|}
\hline Items & Ramp type demand & Quadratic demand \\
\hline Holding cost & 71.86 & 51.72 \\
\hline Setup cost & 81.97 & 98.04 \\
\hline Total cost & 161.02 & 154.93 \\
\hline
\end{tabular}

\section{Comparative study between two models}

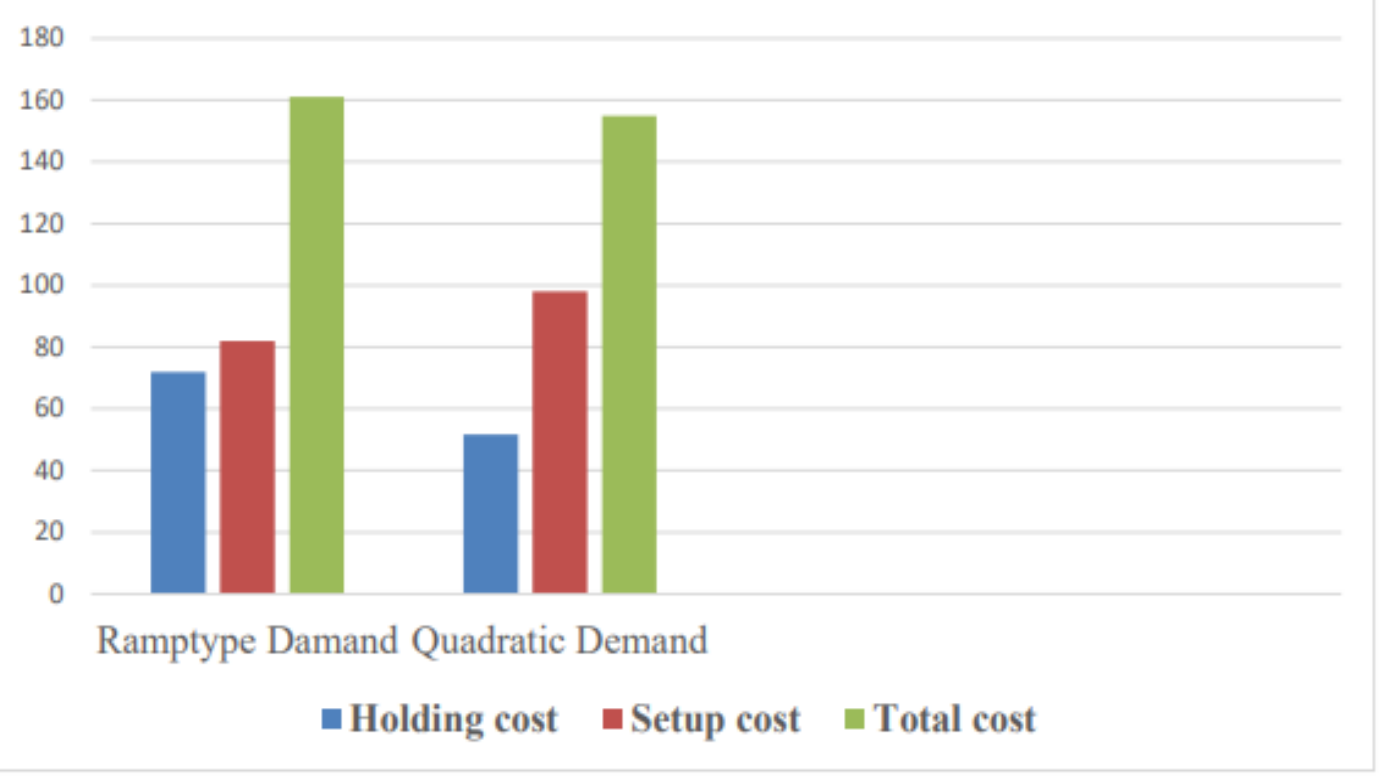




\section{CONCLUDING REMARKS}

In this study, we have carried out two types of inventory models for deteriorating items with ramptype demand and quadratic demand in nature. The models are developed analytically as well as computationally. Numerical examples and sensitivity analysis of the solutions have been performed separately.

We have also done comparative study on holding cost, setup cost and total cost of the two types of models. It is observed from the analytical and graphical presentation that holding cost and total cost for model having quadratic demand rate are less than that of model having ramptype demand rate. On the other hand setup cost behaviour is opposite. So, holding cost and total cost in quadratic function demand are better to compare of ramptype demand and special attention is made on the inventory model having quadratic function of demand rate.

\section{REFERENCES}

(1) Donaldson W.A.,(1977) "Inventory replenishment policy for a linear trend in demand - An analytical solution”, Operations Research Quarterly,Vol. 28, pp663-670.

(2) Silver E.A.,(1979) "A simple inventory decision rule for a linear trend in Demand",J. Operational Research Society, Vol. 30, pp71-75.

(3) Mandal B.\& Pal A.K., (1988) "Order Level inventory system with ramp type demand rate", J. International Mathematics, Vol 1, No. 1, pp49-66.

(4) BiswaranjanMandal, (2010) "An EOQ inventory model for weibull distributed deteriorated items under ramp type demand and shortages", OPSEARCH, Indian J. of Operations Research, Vol 47, No. 2, pp158-165.

(5) Minghao Cheng, Bixi Zhang \&Guoquing Wang, (2011) "Optimal policy for deteriorating items with trapezoidal type demand and partial backlogging”, Applied Mathematical Modelling,Vol. 35, pp35523560 .

(6) Ghosh S. K., Sarkar T. \&Chaudhuri K.S., (2012) “ An optimum inventory replenishment policy for a deteriorating item with time-quadratic demand and time dependent partial backlogging with shortages in all cycles", Applied Mathematics and Computation, Vol. 218, pp 9147-9155. 